\title{
Effect of matching microalgal strains origin and regional weather condition on biomass productivity in environmental photobioreactors
}

\author{
Camila D. Coronel, Mauro Do Nascimento, Leonardo Curatti* \\ Instituto de Investigaciones en Biodiversidad y Biotecnología (INBIOTEC-CONICET), Mar del Plata, Argentina
}

\section{A R T I C L E I N F O}

\section{Keywords:}

Microalgae

Bioprospecting

High irradiance

Scenedesmus spp.

Biomass productivity

Environmental photobioreactor

\begin{abstract}
A B S T R A C T
It is generally assumed that increased microalgal biomass productivity on any particular geographical site would be most likely achieved by strains native to that region. However, direct assessment of that hypothesis remains challenging. Here we isolated and biochemically characterized twenty-six microalgal strains from one of the regions with the highest irradiances of the planet. Biomass and lipids productivity of phylogenetically-close Scenedesmus strains native to regions of contrasting irradiances performed similarly under laboratory culture conditions. Culture simulations in environmental photobioreactors, mimicking regional weather conditions, broadly showed physiological responses of these strains according to their origin. However, under the mean weather conditions of a predicted highly productive region, an exotic strain from a lower irradiance zone resulted $40 \%$ more productive than a phylogenetically close-relative native strain. These results challenge the generalized view of the convenience of using native microalgae to increase productivity and broadens the discussion towards alternative scenarios.
\end{abstract}

\section{Introduction}

Microalgal biomass can contribute significantly to expanding the availability of feedstocks for biofuels in most temperate regions of the world. This statement is based on the potential for high productivity of algae while using non-arable land, brackish water or salt water, and on the possibility of using waste nutrients and effluents. However, microalgal production costs, biomass harvesting and conversion into biofuels must be significantly reduced to about 5 -fold to reach DOE targets set for 2022 for commercial feasibility. Microalgae production is the most expensive operation accounting for about $65 \%$ either for current or projected production costs towards 2022 (Department of Energy, 2014; Slade and Bauen, 2013).

A key challenge to address this problem is increasing the annual biomass productivity from the current state-of-the-art productivity of $8.5 \mathrm{~g} \cdot \mathrm{m}^{-2} \cdot$ day $^{-1}$ to $25 \mathrm{~g} \cdot \mathrm{m}^{-2} \cdot \mathrm{day}^{-1}$ that would be required to approach target production costs (Huesemann et al., 2018).

It is anticipated that increased productivity in open pond systems would result from the integration of technology development together with strategic assessments of resources to operate sustainable algal systems. Resource assessment comprises weather conditions such as solar irradiance, temperature, precipitation regime, wind, etc.; nonarable land and land slope; non-potable water, waste-nutrient streams and waste $\mathrm{CO}_{2}$; supporting transport infrastructure to access downstream conversion processing; and isolation and characterization of local microalgal strains (Lammers et al., 2017).

The convenience of using highly competitive local species has been consistently suggested (Lammers et al., 2017) since pioneering efforts such as the DOE Aquatic Species Program (Benemann and Oswald, 1996). It has been shown more recently that desmid microalgae (Stamenković and Hanelt, 2013) and Chlorella spp. (Barati et al., 2018) strains displayed physiological responses towards temperature that matched the locations from which they had been isolated.

Many attempts have been made for algal biomass production modeling and climate-simulated culturing. Light and temperature are the main abiotic determinants of biomass productivity in photobioreactors and ponds operated under well-mixed and nutrient-replete conditions. For example, Huesemann et al. (2013) developed a model which uses only two physical (incident light intensity and culture depth) and two species-specific biological input parameters (biomass light absorption coefficient and the specific growth rate as a function of light intensity) for predicting the biomass growth rates (Huesemann et al., 2013). Other productivity prediction models included as input variables gas-to-liquid mass transfer, algal uptake of carbon dioxide, algal growth kinetics, and light and temperature (Pegallapati and Nirmalakhandan, 2012). Another study integrated a microalgae growth model with hourly historical meteorological data from global locations for the assessment of the productivity potential of microalgae cultivated

\footnotetext{
* Corresponding author at: Instituto de Investigaciones en Biodiversidad y Biotecnología (INBIOTEC), Vieytes 3103, Mar del Plata 7600, Argentina.

E-mail address: lcuratti@inbiotec.conicet.gov.ar (L. Curatti).
} 
in closed photobioreactors. This analysis suggested an average world productivity of $9.4 \mathrm{~g} \cdot \mathrm{m}^{-2} \cdot \mathrm{day}^{-1}$ and up to $15 \mathrm{~g} \cdot \mathrm{m}^{-2} \cdot \mathrm{day}^{-1}$ in some geographical regions, such as Australia, Brazil, Colombia, Egypt, Ethiopia, India, Kenya, and Saudi Arabia, predicted as highly productive (Moody et al., 2014).

More recently, last generation culturing systems such as indoor raceways at Pacific Northwest National Laboratory (Huesemann et al., 2017) and the Phenometrics environmental Photobioreactors ${ }^{\mathrm{TM}}$ (ePBRs) (Lucker et al., 2014), controlling LED-light intensity and temperature, allowed simulating open pond culture conditions at different geographical regions. These devises brought a low-risk and cost-effective way of screening strains for their potential of exhibiting high biomass productivities in outdoor ponds, for finding the best match for a given strain and a specific geographic location, and for identifying the optimum pond operating conditions (Lammers et al., 2017).

Resource assessment and algal productivity models suggested South America and Africa as two of the continents with higher potential for massive culture of microalgae (Moody et al., 2014). Bioprospecting efforts for biotechnologically relevant microalgal strains in South America have been quite recent and modest either in number or in prospecting effort with a few exceptions mostly in Brazil, and Argentina, (Araujo et al., 2011; Do Nascimento et al., 2012; Nascimento et al., 2013; Sanchez Rizza et al., 2017).

In this study we compared the productivity of oleaginous microalgal strains identified after bioprospecting studies from two Argentinian eco-regions with contrasting solar irradiation and temperature. By ePBR simulations of Scenedesmus obliquus strains productivity in open ponds we observed a differential irradiance-dependent maximal biomass productivity according to the strains origin. However, the overall higher areal biomass and lipid productivity corresponded to the strain native to the low-irradiance site under the mean weather conditions of the higher irradiance site in deeper open raceway-ponds.

\section{Materials and methods}

\subsection{Microalgae isolation}

Microalgae bioprospecting and isolation were conducted essentially as Do Nascimento and colleagues (Do Nascimento et al., 2012) with modifications. Briefly, freshwater samples were collected from of Jujuy, Argentina $\left(24^{\circ} 11^{\prime} 08^{\prime \prime} \mathrm{S} 65^{\circ} 17^{\prime} 58^{\prime \prime} \mathrm{W}\right)$ during January and March in 2016. Samples were supplemented with $\mathrm{BG} 11_{0}$ medium (Rippka et al., 1979) containing $3 \mathrm{mM} \mathrm{NaNO}_{3}$ as the nitrogen source. Cultures were incubated at $29 \pm 1{ }^{\circ} \mathrm{C}$ and constant light at $310 \mu \mathrm{mol}$ photons $\mathrm{m}^{-2} \cdot \mathrm{s}^{-1}$. After enrichment for a few months, dominant strains were isolated by serial dilution or streaking onto solid medium. Monoalgal condition of the cultures and axenicity were ascertained by observation under a microscope and cultivation on LB medium for the presence of heterotrophic bacteria, respectively.

\subsection{Microalgal strains identification}

\subsubsection{Morphological determination}

Strains were preliminary identified by observation of morphological characters under a microscope and using taxonomic keys (Bourrelly, 1966).

\subsubsection{Ribotypification and sequence analysis}

Taxonomic determination was further confirmed by sequencing a ribosomal RNA region comprising ITS1-5.8S-ITS2 as reported before (Do Nascimento et al., 2012). Total DNA was extracted from $10^{7}$ to $10^{8}$ microalgal cells in $400 \mu \mathrm{L}$ of TE buffer $(10 \mathrm{mM}$ Tris- $\mathrm{HCl}, \mathrm{pH} 8.0$ and $1 \mathrm{mM}$ EDTA) containing $0.5 \%$ SDS, $200 \mu \mathrm{L}$ phenol and $200 \mu \mathrm{L}$ chloroform. The aqueous phase was further extracted with phenol and chloroform and then DNA was precipitated in the presence of $0.3 \mathrm{M}$ sodium acetate and $1 \mathrm{~mL}$ of ice-cold ethanol. DNA was collected by centrifugation at $13,000 \mathrm{rpm}$ for $15 \mathrm{~min}$, washed once with $1 \mathrm{~mL}$ of ice-cold $70 \%$ ethanol, air dried and finally resuspended in $40 \mu \mathrm{L}$ of deionized water. PCR analysis was conducted using the oligonucleotides 5'-GAAGTCGTAACAAGGTTTCC-3' (forward) and 5'-TCCTGGTTA GTTTCTTTTCC-3' (reverse) (Timmins et al., 2009). PCR products were analyzed by $1 \%$ agarose gels electrophoresis and sent to a sequencing facility (Macrogen Inc., Seoul, South Korea) for the corresponding analysis. Sequencing results were analyzed with Basic Local Alignment Searching Tool (BLAST) by The National Center for Biotechnology Information (http://blast.ncbi.nlm.nih.gov) and by multiple sequence analysis using the Clustal W algorithm from The Molecular Evolutionary Genetics Analysis v7 (MEGA7) software (Kumar et al., 2008). Phylogenetic trees were created using the Neighbor Joining algorithm from the MEGA7 software after 1000 rounds of bootstrap resampling.

\subsection{Microalgae cultivation}

Cultivation of microalgae was conducted as described before (Do Nascimento et al., 2012; Sanchez Rizza et al., 2017) with minor modifications. For biomass characterization, microalgal strains were cultivated indoors in $500 \mathrm{~mL}$ sterilized glass bottles containing $300 \mathrm{~mL}$ BG11 $1_{0}$ medium containing $1 \mathrm{mM} \mathrm{NaNO}_{3}$ (N-deficiency) sparged with filtered air from the bottom. Cultures were incubated at $29 \pm 1{ }^{\circ} \mathrm{C}$ under constant light at $380 \mu \mathrm{mol}$ photons $\mathrm{m}^{-2} \cdot \mathrm{s}^{-1}$.

For a detailed analysis of biomass productivity and biomass biochemical composition, we used the microalgal strains $S$. obliquus C1S and Desmodesmus sp. FG isolated from South-Eastern Buenos Aires (Do Nascimento et al., 2012) and Scenedesmus sp. P31 and Desmodesmus sp. P5 isolated from the province of Jujuy. These different geographical regions were selected for their different climatic conditions, specially their contrasting irradiance regime. Microalgae strains were cultivated in $500 \mathrm{~mL}$ sterilized glass bottles sparged with filtered air from the

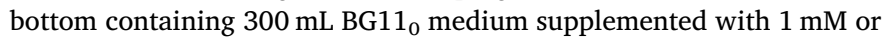
$6 \mathrm{mM} \mathrm{NaNO}_{3}$ at $29 \pm 1{ }^{\circ} \mathrm{C}$ under high $\left(310 \mu \mathrm{mol}\right.$ photons $\left.\mathrm{m}^{-2} \cdot \mathrm{s}^{-1}\right)$ or low $\left(110 \mu \mathrm{mol}\right.$ photons $\left.\mathrm{m}^{-2} \cdot \mathrm{s}^{-1}\right)$ irradiance conditions.

For cultivation in environmental photobioreactors, two Phenometrics ${ }^{\mathrm{TM}}$ ePBR laboratory benchtop photobioreactors were used (Fig. 1). The ePBR was designed to simulate the environmental conditions prevailing in outdoor algal production ponds, with a special focus on light penetration (Lucker et al., 2014). The culture volume of each reactor was $460 \mathrm{~mL}$ or $90 \mathrm{~mL}$ of $\mathrm{BG} 11_{0}$ medium containing $6 \mathrm{mM}$ $\mathrm{NaNO}_{3}$ to achieve a simulated pond's depth of $20 \mathrm{~cm}$ or $5 \mathrm{~cm}$, respectively. Simulated weather conditions are sown in Table 1 . The selected conditions were mean autumn weather in Buenos Aires or Jujuy and a hypothetical extreme condition of a fully sunny month in spring in Jujuy, which was set from data registered by the NASA, USA (maximum irradiance of $2850 \mu \mathrm{mol}$ photons $\mathrm{m}^{-2} \cdot \mathrm{s}^{-1}$ and 15 light hours per day on November 2004). For $5 \mathrm{~cm}$ simulated ponds the light source was set at $2850 \mu \mathrm{mol}$ photons $\mathrm{m}^{-2} \cdot \mathrm{s}^{-1}$ as calibrated for $20 \mathrm{~cm}$ ponds for a determined light intensity of $1850 \mu \mathrm{mol}$ photons $\mathrm{m}^{-2} \cdot \mathrm{s}^{-1}$ on the cultures surface. Biomass productivity was calculated from biomass dry weight when cultures reached stationary phase.

\subsection{Analytical methods}

Most analytical methods were described by Sanchez Rizza et al. (Sanchez Rizza et al., 2017). Cell density was estimated by OD at $750 \mathrm{~nm}$ and biomass dry weight was determined by drying out culture samples in an oven at $70{ }^{\circ} \mathrm{C}$ until constant weight (2-3 days). For biomass total protein determination, samples were heated at $100{ }^{\circ} \mathrm{C}$ for $10 \mathrm{~min}$ in the presence of $1 \mathrm{~N} \mathrm{NaOH}$ (Pruvost et al., 2011) and then protein determination was conducted following the Lowry's method (Lowry et al., 1951) using $\mathrm{NaOH}$-treated bovine serum albumin as a standard. For biomass total carbohydrates determination, samples were reacted with the anthrone reagent (Dreywood, 1946) and carbohydrates content was calculated from a standard curve using glucose. 
A

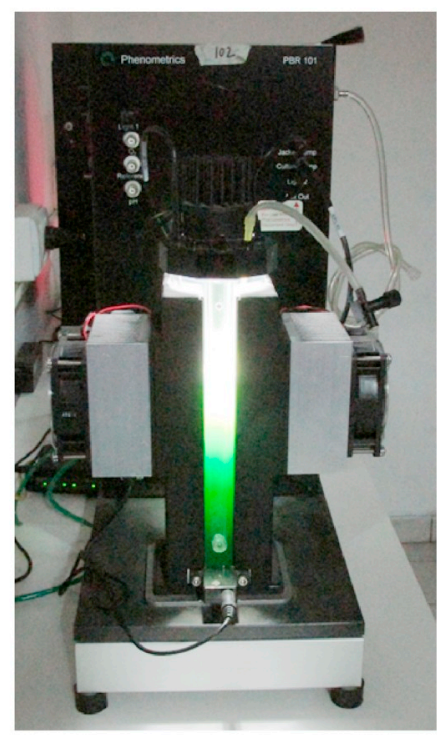

B

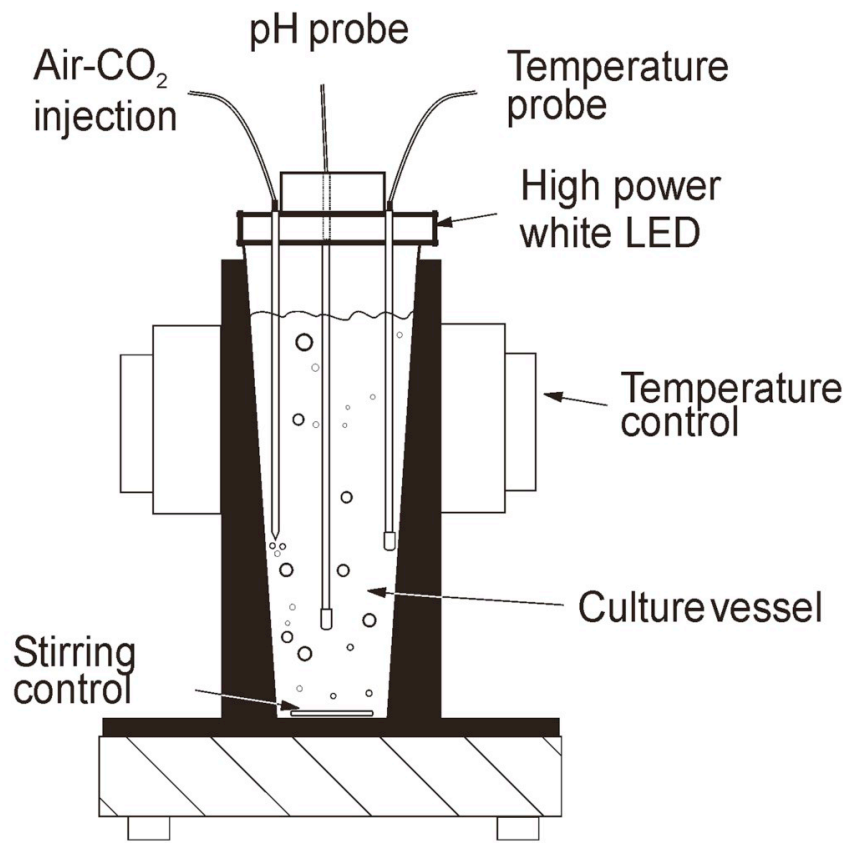

Fig. 1. Phenometrix TM environmental photobioreactor (ePBR). A, picture; B, schematic (front views).
Total lipids were determined gravimetrically after lipids extraction basically according to Bligh and Dyer (Bligh and Dyer, 1959) with modifications (Do Nascimento et al., 2012) or by the sulfo-phosphovanillin method (Mishra et al., 2014) using commercial canola oil as lipid standard. Carotenoids were quantified spectrophotometrically from the lipid fractions obtained by the modified Bligh and Dyer method and the equations proposed by Wellburn (Wellburn, 1994).

\section{Results and discussion}

\subsection{Isolation and identification of microalgal strains from Jujuy, Argentina}

We had previously assembled a collection of thirty-four microalgal strains from different continental freshwater environments from Southeastern Buenos Aires, Argentina $\left(38^{\circ} 0^{\prime} 0^{\prime \prime} \mathrm{S} 57^{\circ} 33^{\prime} 0^{\prime \prime} \mathrm{W}\right)$ at sea level. Strains had been primarily identified by cell morphology and taxonomical classification, which was further refined by sequence analysis of their ribosomal RNA region comprising ITS1-5.8S-ITS2. After biochemical characterization of the biomass and indoors and outdoors growth performance, Scenedesmus obliquus strain C1S, was identified as one of the most promising strains of the collection for technological applications (Do Nascimento et al., 2012).

According to a previous global model of microalgal productivity from regional weather inputs, and temperature- and light-dependent productivity of Nannochloropsis sp. data, Southeastern Buenos Aires would rank as a low- to mild-productive geographical region. The study also suggested that the Northwestern part of the country would be one of the most productive sites in South America (Moody et al., 2014) (Fig. 2).

Jujuy, Argentina $\left(24^{\circ} 11^{\prime} 08^{\prime \prime} \mathrm{S} 65^{\circ} 17^{\prime} 58^{\prime \prime} \mathrm{W}\right)$ with a mean altitude of $3433 \mathrm{~m}$ above sea level presents one of the highest mean irradiances over the planet's surface at $7.5 \mathrm{kwh} \cdot \mathrm{m}^{2} \cdot \mathrm{day}^{-1}$ (Rondanelli et al., 2015).

For this study, we assembled a collection of microalgal strains native from Jujuy. Samples were collected from various freshwater natural or artificial ponds from summer to autumn 2016. From the cultures that displayed the highest growth robustness, twenty-six monoalgal cultures were established. Fig. 3 shows a neighbor joining phylogenetic tree depicting the relatedness of the native strains ribosomal RNA region with selected sequences from the public databases. Although representative strains from most Chlorophyta clades were isolated, an apparent redundancy of closely related Desmodesmus strains was observed.

For a preliminary assessment of the biotechnological potential of the native strains, carbon reserves accumulation was induced by culturing the microalgae under a limiting amount of nitrogen $\left(1 \mathrm{mM} \mathrm{NO}_{3}{ }^{-}\right)$and high light irradiance (constant $380 \mu \mathrm{mol}$ photons $\mathrm{m}^{-2} \cdot \mathrm{s}^{-1}$ ) for 10 days. As shown in Table 2, under these conditions a few strains (F21, F22, and Prm) accumulated carbohydrates over $50 \%(\mathrm{w} / \mathrm{w})$ and could be regarded as potentially interesting feedstocks for bioethanol. Most Desmodesmus strains, accumulated lipids up to about $40 \%(\mathrm{w} / \mathrm{w})$ suggesting potential as biodiesel feedstocks. As expected, higher levels of lipids were revealed by the sulpho-phospho-vanillin method than by the modified Blight and Dyer procedure for lipids extraction with organic

Table 1

Culture conditions in environmental photobioreactors.

\begin{tabular}{|c|c|c|c|c|}
\hline Condition & Buenos Aires mean 20 & Jujuy mean 20 & Jujuy sunny ${ }^{\mathrm{b}} 20$ & Jujuy sunny 5 \\
\hline Growth medium & $\mathrm{BG}_{1} 1_{0}, 6 \mathrm{mM} \mathrm{NaNO}{ }_{3}$ & $\mathrm{BG} 11_{0}, 6 \mathrm{mM}$ NaNO3 & $\mathrm{BG} 11_{0}, 6 \mathrm{mM}$ NaNO3 & $\mathrm{BG} 11_{0}, 6 \mathrm{mM}$ NaNO3 \\
\hline Culture depth (cm) & 20 & 20 & 20 & 5 \\
\hline Temperature $\left({ }^{\circ} \mathrm{C}\right)$ & $16 \pm 4$ & $12 \pm 8$ & $14 \pm 9$ & $14 \pm 9$ \\
\hline Max. irradiance ${ }^{c}\left(\mu \mathrm{mol}\right.$ photons $\left.\mathrm{m}^{-2} \mathrm{~s}^{-1}\right)$ & 838 & 1501 & 2850 & 1850 \\
\hline Day duration (h) & 12 & 12 & 15 & 15 \\
\hline
\end{tabular}

\footnotetext{
a Mean weather conditions in autumn.

b Only sunny days in spring.

c On the culture's surface.
} 


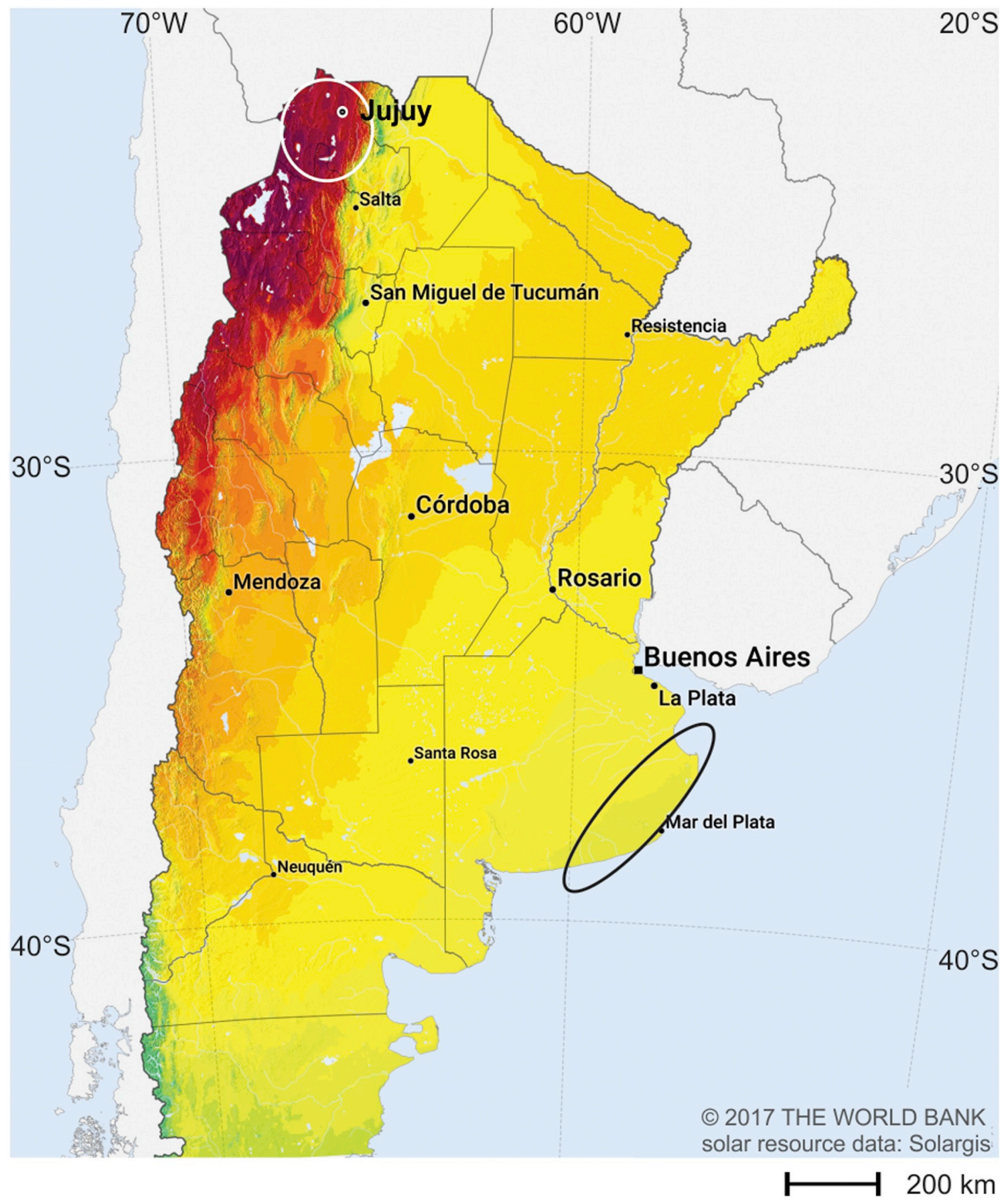

\section{Long term average of $\mathrm{GHI}$, period 1999-2015 $\left(\mathrm{kWh} / \mathrm{m}^{2}\right)$}

\begin{tabular}{lccccccccc|} 
Daily totals: & 4.0 & 4.4 & 4.8 & 5.2 & 5.6 & 6.0 & 6.4 & 6.8 & 7.2 \\
Yearly totals: & 1461 & 1607 & 1753 & 1899 & 2045 & 2191 & 2337 & 2483 & 2629
\end{tabular}

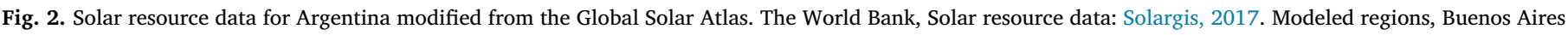
and Jujuy, were highlighted in circles.

solvents and gravimetric determination (Mishra et al., 2014). The most dramatic discrepancy was observed for biomass of strain Chlamydomonas sp. strain F22. It is known that the Blight and Dyer method may underestimate oil content due to suboptimal extraction from microalgae with thick (or hard-to-break) cell walls (Baudelet et al., 2017). On the other hand, the sulpho-phospho-vanillin method is sensitive to the level of unsaturation of the fatty acids in the samples, and might also be less accurate in some cases (Mishra et al., 2014). The specific optimization of methods for accurate determination of lipids in every single strain of this collection might correspond to a separate work and thus is beyond the scope of this study. Nevertheless, high lipid content and/or reactivity, together with low accumulation levels of carbohydrates 
upon nitrogen starvation, agrees with a general trend for oleaginous microalgae (Do Nascimento et al., 2012; Li et al., 2010; Sanchez Rizza et al., 2017).

Most of the strains of the collection developed yellow to orange

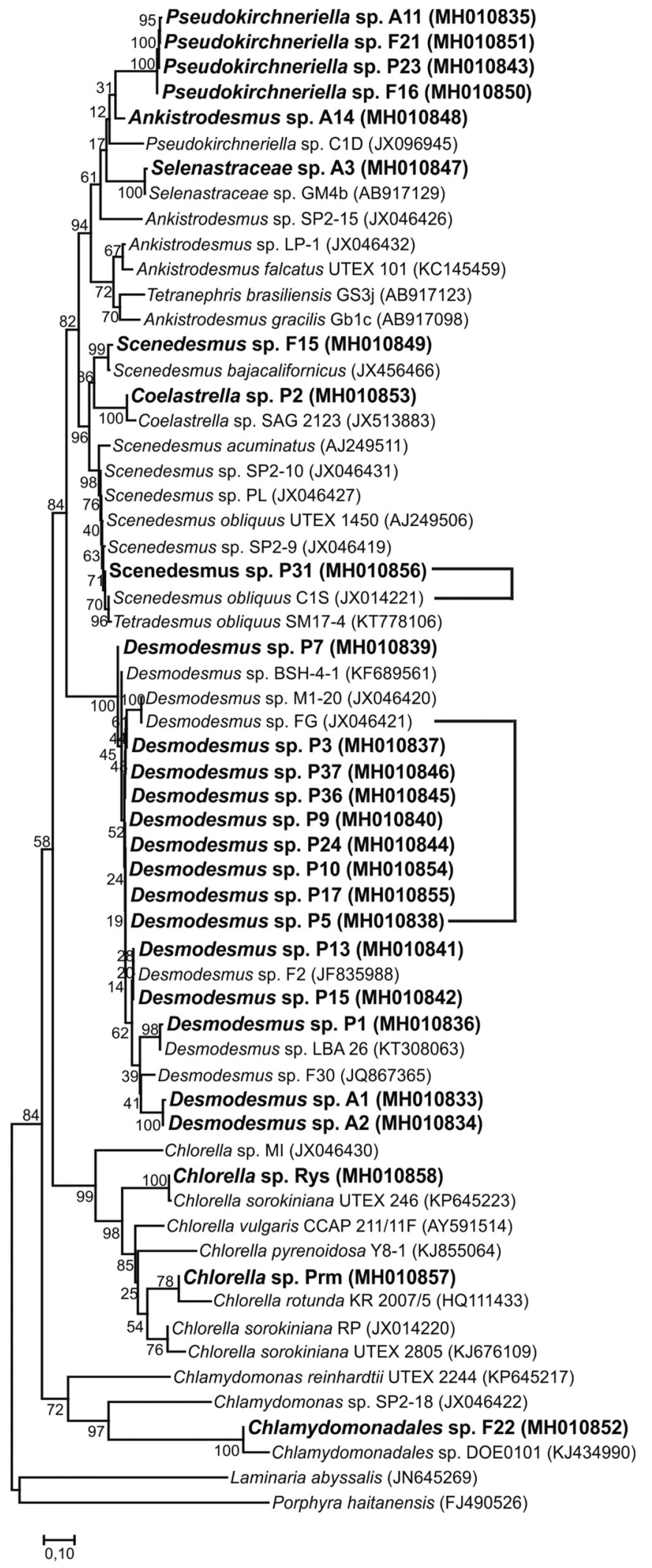

${ }_{95}$ Pseudokirchneriella sp. A11 (MH010835)

100. Pseudokirchneriella sp. F21 (MH010851)

100. Pseudokirchneriella sp. P23 (MH010843)

Ankistrodesmus sp. A14 (MH010848)

Pseudokirchneriella sp. C1D (JX096945)

Ankistrodesmus sp. LP-1 (JX046432)

100 Loelastrella sp. SAG 2123 (JX513883)

Scenedesmus acuminatus (AJ249511)

4 Scenedesmus sp. SP2-10 (JX046431)

76 Scenedesmus sp. PL (JX046427)

40 Scenedesmus obliquus UTEX 1450 (AJ249506)

Scenedesmus sp. SP2-9 (JX046419)

7 Scenedesmus sp. P31 (MH010856)

Scenedesmus obliquus C1S (JX014221)

Tetradesmus obliquus SM17-4 (KT778106)

Desmodesmus sp. P3 (MH010837)

Desmodesmus sp. P37 (MH010846)

Desmodesmus sp. P17 (MH010855)

19 Desmodesmus sp. P5 (MH010838)

Desmodesmus sp. P13 (MH010841)

smus sp. F2 (JF835988)

98 Desmodesmus sp. P1 (MH010836)

Desmodesmus sp. LBA 26 (KT308063)

9 -Desmodesmus sp. F30 (JQ867365)

Desmodesmus sp. A1 (MH010833)

Chlorella sp. MI (JX046430)

Chlorella soroki

98 Chlorella vulgaris CCAP 211/11

54 Chlorella sorokiniana RP (JX014220)

76 Chlorella sorokiniana UTEX 2805 (KJ676109)

Chlamydomonas sp. SP2-18 (JX046422)

Chlamydomonadales sp. F22 (MH010852)

(KJ434990)

0,10
Fig. 3. Phylogenetic analysis of the rRNA ITS1-5.8S-ITS2 region of the native microalgae isolated from Jujuy, Argentina. The sequences corresponding to the strains isolated in this work were indicated in bold case and the corresponding GeneBank accession numbers were indicated. The multiple sequence alignments were generated using the Clustal $\mathrm{W}$ algorithm from The Molecular Evolutionary Genetics Analysis v7 (MEGA7) software. Phylogenetic trees were created using the Neighbor Joining algorithm from the MEGA7 software after 1000 rounds of bootstrap resampling. The relatedness of strains C1S and P31 and FG and P5 is shown by connecting lines on the right.

pigments by the sampling time of this screening. Spectrophotometric analysis suggested that some of the strains, especially A3 and A14, can accumulate carotenoids at about $0.3 \%(\mathrm{w} / \mathrm{w})$. This would place them as candidate strains to further explore their potential as pigments producers, although considerably behind other well studied species such as Dunaliella salina or Haematococcus pluvialis (Del Campo et al., 2007; Spolaore et al., 2006).

3.2. Comparison of biomass productivity of selected native strains from lowor high-irradiance geographical sites

It is broadly assumed that native microalgal strains might display a more robust growth and productivity for any specific geographical site. This postulate is conceptually appealing, and among other ecological concerns, supports most bioprospecting efforts globally (Araujo et al., 2011; Do Nascimento et al., 2012; Lammers et al., 2017; Mutanda et al., 2011; Nascimento et al., 2013; Sanchez Rizza et al., 2017; Sheehan et al., 1998; Steinrücken et al., 2017).

However, it has been extremely challenging to analyze whether or how much "elite" strains can acclimate to proliferate in specific geographical regions regardless of its origin and the contribution of matching the strain origin and the geographical site of cultivation (natural selection) for higher biomass productivity. This assessment might entail large outdoors facilities at different sites, enough replicas over several years to account for local weather variability and permission for outdoors testing of exotic strains.

Having a microalgal culture collection from two geographical sites with contrasting irradiance conditions (Buenos Aires and Jujuy) gave us the opportunity to investigate some aspects of native strains adaptability to specific environmental conditions.

Thus, we selected two pairs of very closely-related strains at the rDNA sequence, one from each geographical region for analysis (Fig. 3). The S. obliquus strains C1S (Buenos Aires) and P31 (Jujuy) are 100\% identical at the rDNA sequence. Strain C1S was only marginally more productive than strain P31 irrespective of nitrogen availability at 1 or $6 \mathrm{mM} \mathrm{NO}_{3}{ }^{-}$or constant light intensities of 110 or $310 \mu \mathrm{mol}$ photons $\mathrm{m}^{-2} \cdot \mathrm{s}^{-1}$, in air-bubbled bottles at $29^{\circ} \mathrm{C}$ (Table 3). Growth curves analysis showed a similar trend (Fig. 4A-D). Biomass composition analysis additionally confirmed the relatedness of strains C1S and P31, since both displayed a very similar reduction in proteins accumulation and an increase in lipids storage when cells were cultivated for 10 days at the expense of $1 \mathrm{mM} \mathrm{NO}_{3}{ }^{-}$(Table 3).

A similar analysis was conducted with the pair of Desmodesmus sp. strains FG (Buenos Aires) and P5 (Jujuy) that share an rDNA sequence identity of $95 \%$. Strain FG from Buenos Aires (lower irradiance site) grew faster strain P5 from Jujuy (higher irradiance site) under all the conditions analyzed (Fig. 4E-H). However, the difference in the apparent growth rate was exacerbated under lower light irradiance (Fig. 4E and G). While strain FG preferentially accumulated carbohydrates upon nitrogen starvation (Sanchez Rizza et al., 2017), strain P5 accumulated lipids up to about $50 \%(\mathrm{w} / \mathrm{w})$ (Table 3$)$. A more detailed analysis of strain FG as a potential feedstock for the production of ethanol has been already conducted (Sanchez Rizza et al., 2017). Likewise, lipids accumulation of strain P5 and biomass processing into biodiesel should be further optimized to ascertain the potential of this strain as a feedstock for that biofuel. 
Table 2

Biochemical biomass composition of microalgae strains isolated from Jujuy.

\begin{tabular}{|c|c|c|c|c|}
\hline Strain & $\begin{array}{l}\text { Carbohydrate } \\
(\% \text { dwt })\end{array}$ & $\begin{array}{l}\text { Protein } \\
\text { (\% dwt) }\end{array}$ & $\begin{array}{l}\text { Lipid }^{\mathrm{a}} \\
\text { (\% dwt) }\end{array}$ & $\begin{array}{l}\text { Carotenoids } \\
\text { (\% dwt) }\end{array}$ \\
\hline Ankistrodesmus sp. A14 & $36,22 \pm 5,33$ & $18,22 \pm 1,16$ & $\begin{aligned} 37,07 & \pm 0,09 \\
(31,89 & \pm 3,62)\end{aligned}$ & $0,30 \pm 0,03$ \\
\hline Chlamydomonales sp. F22 & $53,49 \pm 8,23$ & $20,58 \pm 5,22$ & $\begin{array}{c}10,26 \pm 0,71 \\
(44,31 \pm 3,42)\end{array}$ & $0,03 \pm 0,02$ \\
\hline Chlorella sp. Prm & $47,58 \pm 12,03$ & $21,90 \pm 2,99$ & $\begin{array}{c}30,42 \pm 5,96 \\
(20,66 \pm 1,32)\end{array}$ & $0,03 \pm 0,01$ \\
\hline Chlorella sp. Rys & $34,07 \pm 0,77$ & $13,56 \pm 1,25$ & $27,10 \pm 1,73(45,50 \pm 3,55)$ & $0,07 \pm 0,02$ \\
\hline Coelastrella sp. P2 & $43,38 \pm 2,78$ & $17,95 \pm 3,32$ & $\begin{array}{c}18,18 \pm 3,45 \\
(39,96 \pm 0,19)\end{array}$ & $0,16 \pm 0,02$ \\
\hline Desmodesmus sp. A1 & $36,73 \pm 6,25$ & $31,61 \pm 2,20$ & $\begin{array}{c}20,27 \pm 0,34 \\
(24,45 \pm 1,16)\end{array}$ & $0,03 \pm 0,02$ \\
\hline Desmodesmus sp. A2 & $36,86 \pm 11,20$ & $29,27 \pm 5,50$ & $\begin{array}{c}20,38 \pm 1,05 \\
(26,17 \pm 1,99)\end{array}$ & $0,03 \pm 0,01$ \\
\hline Desmodesmus sp. P1 & $42,31 \pm 0,86$ & $22,34 \pm 2,14$ & $\begin{array}{l}26,93 \pm 0,85 \\
\quad(41,02)\end{array}$ & $0,04 \pm 0,01$ \\
\hline Desmodesmus sp P3 & $31,93 \pm 3,33$ & $24,88 \pm 2,76$ & $\begin{array}{c}25,21 \pm 2,12 \\
(32,24 \pm 4,28)\end{array}$ & $0,07 \pm 0,01$ \\
\hline Desmodesmus sp. P5 & $29,37 \pm 1,19$ & $22,89 \pm 5,25$ & $27,24 \pm 1,24(46,45 \pm 1,65)$ & $0,10 \pm 0,00$ \\
\hline Desmodesmus sp. P7 & $24,10 \pm 2,64$ & $21,60 \pm 3,75$ & $\begin{array}{c}25,38 \pm 7,85 \\
(48,59 \pm 2,18)\end{array}$ & $0,08 \pm 0,04$ \\
\hline Desmodesmus sp. P9 & $38,39 \pm 0,65$ & $23,33 \pm 8,21$ & $\begin{array}{c}21,50 \pm 1,46 \\
(35,19 \pm 1,91)\end{array}$ & $0,10 \pm 0,02$ \\
\hline Desmodesmus sp. P10 & $23,00 \pm 1,88$ & $22,59 \pm 0,43$ & $\begin{aligned} 30,40 & \pm 0,20 \\
(47,76 & \pm 6,40)\end{aligned}$ & $0,09 \pm 0,02$ \\
\hline Desmodesmus sp. P13 & $30,41 \pm 3,90$ & $24,50 \pm 3,64$ & $\begin{array}{c}26,13 \pm 1,61 \\
(39,11 \pm 0,76)\end{array}$ & $0,05 \pm 0,02$ \\
\hline Desmodesmus sp. P15 & $41,31 \pm 2,04$ & $14,44 \pm 3,31$ & $\begin{array}{c}22,28 \pm 3,51 \\
(40,84 \pm 4,84)\end{array}$ & $0,03 \pm 0,01$ \\
\hline Desmodesmus sp. P17 & $35,60 \pm 3,57$ & $23,15 \pm 2,60$ & $\begin{aligned} 25,96 & \pm 5,44 \\
(48,98 & \pm 4,93)\end{aligned}$ & $0,10 \pm 0,04$ \\
\hline Desmodesmus sp. P24 & $26,45 \pm 1,88$ & $26,77 \pm 0,05$ & $\begin{aligned} 32,19 & \pm 0,68 \\
(47,01 & \pm 1,21)\end{aligned}$ & $0,10 \pm 0,02$ \\
\hline Desmodesmus sp. P36 & $40,34 \pm 4,64$ & $25,85 \pm 0,27$ & $\begin{aligned} 22,55 & \pm 0,49 \\
(32,20 & \pm 2,58)\end{aligned}$ & $0,07 \pm 0,03$ \\
\hline Desmodesmus sp. P37 & $39,05 \pm 5,49$ & $27,04 \pm 1,73$ & $\begin{array}{c}21,84 \pm 5,51 \\
(36,81 \pm 8,17)\end{array}$ & $0,07 \pm 0,00$ \\
\hline Pseudokirchneriella sp. A11 & $36,48 \pm 0,42$ & $23,76 \pm 5,88$ & $\begin{array}{c}34,58 \pm 0,15 \\
(39,34 \pm 2,36)\end{array}$ & $0,11 \pm 0,01$ \\
\hline Pseudokirchneriella sp. F16 & $48,76 \pm 2,39$ & $18,46 \pm 6,40$ & $\begin{array}{c}30,17 \pm 1,50 \\
(32,63 \pm 0,06)\end{array}$ & $0,12 \pm 0,04$ \\
\hline Pseudokirchneriella sp. F21 & $52,09 \pm 3,32$ & $19,48 \pm 3,08$ & $\begin{array}{c}30,14 \pm 2,23 \\
(33,94 \pm 0,57)\end{array}$ & $0,15 \pm 0,04$ \\
\hline Pseudokirchneriella sp. P23 & $33,97 \pm 1,98$ & $27,85 \pm 6,20$ & $\begin{aligned} 30,68 & \pm 0,72 \\
(44,63 & \pm 1,47)\end{aligned}$ & $0,09 \pm 0,01$ \\
\hline Scenedesmus sp. F15 & $49,89 \pm 2,11$ & $16,82 \pm 1,60$ & $\begin{aligned} 28,71 & \pm 3,18 \\
(35,96 & \pm 3,35)\end{aligned}$ & $0,13 \pm 0,00$ \\
\hline Scenedesmus sp. P31 & $47,02 \pm 1,44$ & $18,14 \pm 2,32$ & $\begin{aligned} 32,39 & \pm 2,35 \\
(25,84 & \pm 2,63)\end{aligned}$ & $0,05 \pm 0,01$ \\
\hline Selenastraceae sp. A3 & $47,20 \pm 2,69$ & $16,63 \pm 2,46$ & $\begin{array}{c}23,78 \pm 1,61 \\
(25,87 \pm 1,49)\end{array}$ & $0,32 \pm 0,09$ \\
\hline
\end{tabular}

Data represent the mean and range of two independent experiments.

a Lipids have been determined gravimetrically, or by the sulfophosphovanillin method (between parentheses).

Table 3

Effect of light and nitrogen availability on the biomass biochemical composition of selected microalgae isolated from contrasting weather sites.

\begin{tabular}{|c|c|c|c|c|c|c|c|c|}
\hline \multirow[t]{2}{*}{ Strain/ $\mathrm{NaNO}_{3}(\mathrm{mM})$} & \multicolumn{4}{|c|}{ Low irradiance $\left(110 \mu \mathrm{mol}\right.$ photons $\left.\mathrm{m}^{-2} \cdot \mathrm{s}^{-1}\right)$} & \multicolumn{4}{|c|}{ High irradiance $\left(310 \mu \mathrm{mol}\right.$ photons $\left.\mathrm{m}^{-2} \cdot \mathrm{s}^{-1}\right)$} \\
\hline & $\begin{array}{l}\text { Final biomass } \\
\left(\mathrm{gdw} \mathrm{L}^{-1}\right)\end{array}$ & $\begin{array}{l}\text { Carbohydrate } \\
\text { (\% dwt) }\end{array}$ & $\begin{array}{l}\text { Protein } \\
(\% d w t)\end{array}$ & $\begin{array}{l}\text { Lipid } \\
\text { (\% dwt) }\end{array}$ & $\begin{array}{l}\text { Final biomass } \\
\left(\mathrm{gdw} \mathrm{L}^{-1}\right)\end{array}$ & $\begin{array}{l}\text { Carbohydrate } \\
\text { (\% dwt) }\end{array}$ & $\begin{array}{l}\text { Protein } \\
(\% d w t)\end{array}$ & $\begin{array}{l}\text { Lipid } \\
\text { (\% dwt) }\end{array}$ \\
\hline $\mathrm{C} 1 \mathrm{~S} / 1$ & $0,89 \pm 0,05$ & $43,14 \pm 1,02$ & $21,87 \pm 1,72$ & $38,26 \pm 4,36$ & $0,86 \pm 0,06$ & $49,19 \pm 1,00$ & $22,29 \pm 1,62$ & $32,24 \pm 0,02$ \\
\hline $\mathrm{P} 31 / 1$ & $0,79 \pm 0,10$ & $45,54 \pm 1,12$ & $23,44 \pm 0,44$ & $39,02 \pm 2,39$ & $0,78 \pm 0,11$ & $46,38 \pm 0,19$ & $23,89 \pm 0,23$ & $36,27 \pm 5,91$ \\
\hline $\mathrm{C} 1 \mathrm{~S} / 6$ & $1,99 \pm 0,13$ & $47,26 \pm 2,38$ & $38,20 \pm 4,01$ & $27,45 \pm 1,64$ & $2,01 \pm 0,05$ & $44,39 \pm 4,50$ & $32,05 \pm 1,46$ & $30,08 \pm 3,38$ \\
\hline $\mathrm{P} 31 / 6$ & $1,81 \pm 0,18$ & $44,87 \pm 3,16$ & $44,50 \pm 2,63$ & $24,43 \pm 0,59$ & $1,74 \pm 0,27$ & $41,25 \pm 0,94$ & $35,25 \pm 0,35$ & $30,39 \pm 3,02$ \\
\hline $\mathrm{FG} / 1$ & $0,84 \pm 0,04$ & $54,72 \pm 1,17$ & $13,22 \pm 4,97$ & $34,08 \pm 2,09$ & $0,84 \pm 0,06$ & $46,20 \pm 5,58$ & $11,66 \pm 1,82$ & $34,95 \pm 0,38$ \\
\hline $\mathrm{P} 5 / 1$ & $0,91 \pm 0,01$ & $36,28 \pm 1,38$ & $11,29 \pm 3,13$ & $46,35 \pm 2,37$ & $0,95 \pm 0,02$ & $31,86 \pm 5,15$ & $16,69 \pm 1,16$ & $56,54 \pm 1,05$ \\
\hline $\mathrm{FG} / 6$ & $1,98 \pm 0,09$ & $48,01 \pm 4,80$ & $36,65 \pm 8,57$ & $20,31 \pm 0,01$ & $2,54 \pm 0,31$ & $48,25 \pm 3,17$ & $29,41 \pm 9,12$ & $25,03 \pm 0,83$ \\
\hline $\mathrm{P} 5 / 6$ & $1,90 \pm 0,09$ & $40,81 \pm 0,87$ & $38,14 \pm 6,00$ & $33,63 \pm 2,99$ & $2,39 \pm 0,34$ & $33,22 \pm 3,60$ & $30,06 \pm 5,05$ & $42,22 \pm 4,49$ \\
\hline
\end{tabular}


A

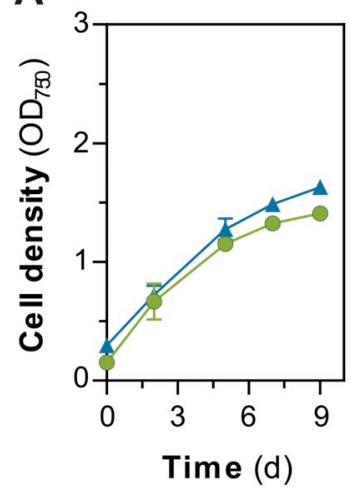

E

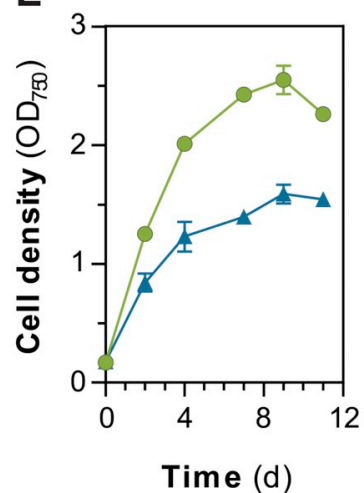

B

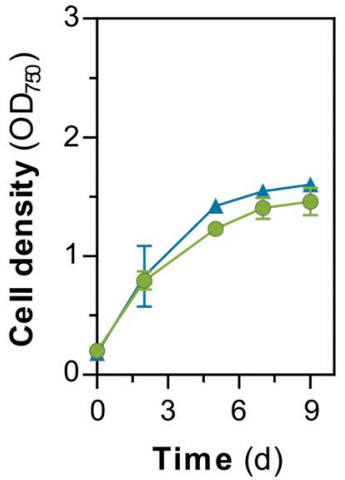

$\mathbf{F}$

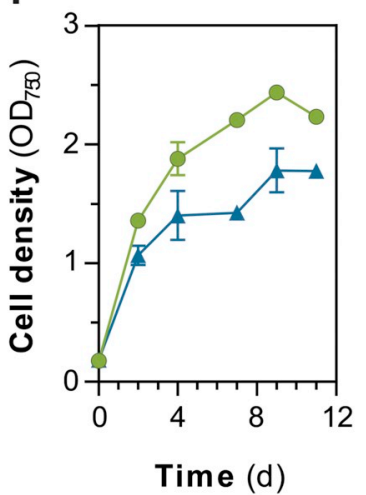

C

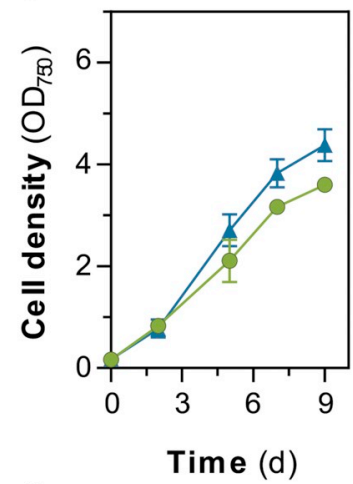

G

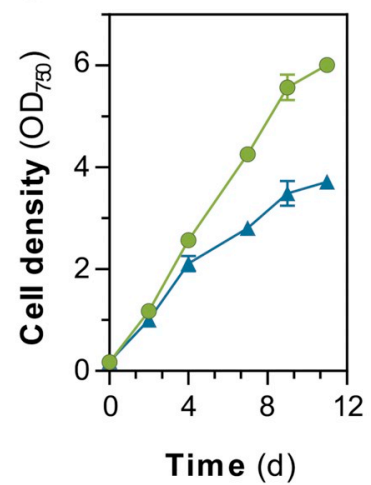

D

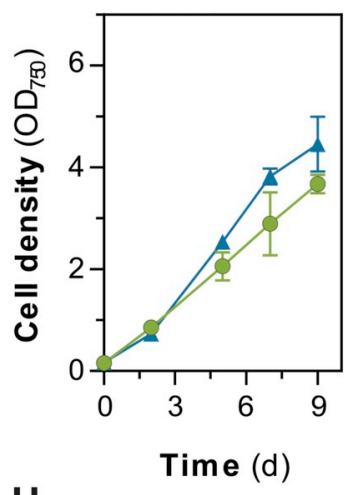

H

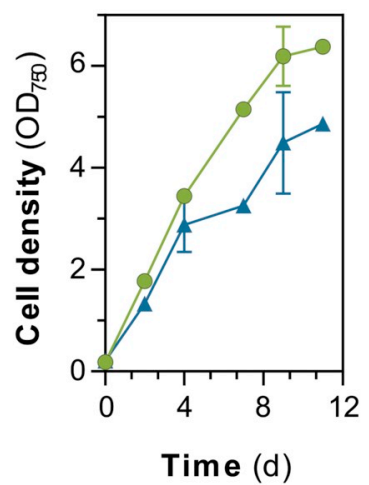

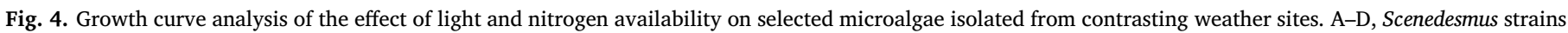

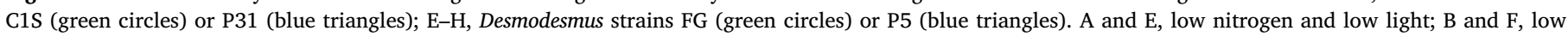

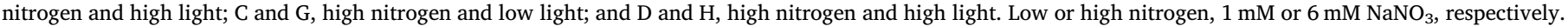

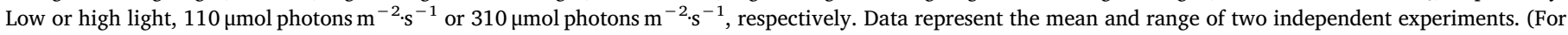
interpretation of the references to color in this figure legend, the reader is referred to the web version of this article.)

To further analyze the effect of matching $S$. obliquus strains origin with local weather conditions on biomass and lipid productivity we run ePBR simulations for a low-risk and cost-effective analysis. Whereas strain C1S has been isolated from Buenos Aires as a robust native strain that successfully competes with other native strains from the same environment (Do Nascimento et al., 2012) or other strains (LoeraQuezada et al., 2016), strain P31 has been chosen among the strains isolated from Jujuy as the strain most similar to C1S but isolated from a geographical site with contrasting weather conditions.

We found that weather (light irradiance and temperature) was most contrasting in autumn between Buenos Aires and Jujuy (Table 1). Also, both strains C1S and P31 have been isolated from its corresponding regions in autumn. Thus, we run an autumn mean weather-condition script on ePBRs simulating $20 \mathrm{~cm}$-deep open ponds (Table 1 ). We found that the strain native to Buenos Aires (C1S) would be only marginally more productive (either areal or volumetric productivity) in Buenos Aires (Fig. 5B-C). Final biomass concentration was about 50\% higher for the local strain (Fig. 5A). This aspect would be noteworthy, since low biomass concentration is one of drawbacks for biomass collection at low cost (Vandamme et al., 2013). Good sedimentation properties to ease cells harvesting has been shown for $S$. obliquus strain C1S (Do Nascimento et al., 2012).

Interestingly, the Buenos Aires strain C1S would be almost $40 \%$ more productive than the native strain P31 in Jujuy in the same season (Fig. 5B-C).

Running a script to simulate only sunny days in spring in Jujuy to exacerbate the effect of high irradiance (see materials and methods) showed a moderate positive effect on biomass productivity by the local strains P31 and a slight decrease in biomass productivity for the Buenos Aires strain C1S for all the analyzed parameters (Fig. 5). Reducing the ponds' depth to $5 \mathrm{~cm}$ to further enhance the high-light effect by decreasing cells shading in the bottom of the simulated ponds resulted in an almost two-fold higher volumetric productivity for both strains, which attained almost identical areal productivities. These results suggested that under the modeled conditions, volumetric productivity was mostly limited by light.

Lipid productivity roughly followed biomass productivity in all conditions and strains tested (Fig. 4D-E). An almost two-fold increase in the lipids content of the biomass was observed for both strains for the simulated $5 \mathrm{~cm}$-depth ponds in only sunny days in Jujuy (Fig. 4D-E). Under these conditions the Buenos Aires strain presented a 23\% higher lipid productivity than the Jujuy strain. Although not further confirmed in this study, we presume that both, higher light irradiance itself and light-dependent enhancement of biomass productivity and nitrogen depletion would contribute to lipids accumulation in both strains, but perhaps more prominently in the Buenos Aires strain C1S.

Overall, this case study suggested that $S$. obliquus strains native to geographical sites with contrasting irradiances tend to show maximal biomass productivities for a given strain according to its origin (C1S at lower and P31 at higher light intensities). A similar trend was observed for the pair of Desmodesmus strains which showed that the Buenos Aires strain (FG) displays an apparent higher growth rate than the Jujuy strain (P5), especially under conditions of lower light irradiance (Fig. 4E and G). Although the structural and/or physiological basis of this observation has not been addressed in this study, we suggest it might be related to differences in photosynthetic efficiency as shown for Cosmarium spp. (Stamenković and Hanelt, 2013) and Chlorella spp. (Barati et al., 2018) strains isolated from different geographical regions from tropical to glacial. It is remarkable that the overall highest biomass productivity of the ePBR simulations corresponded to the Buenos 
A

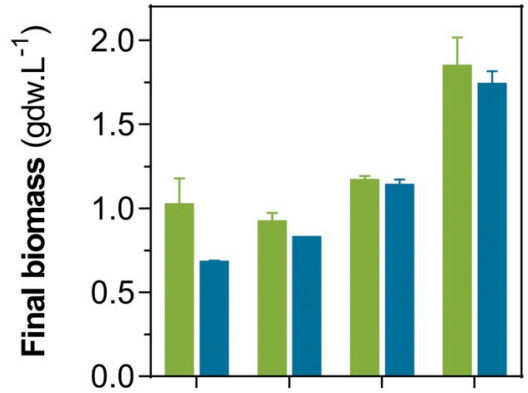

B

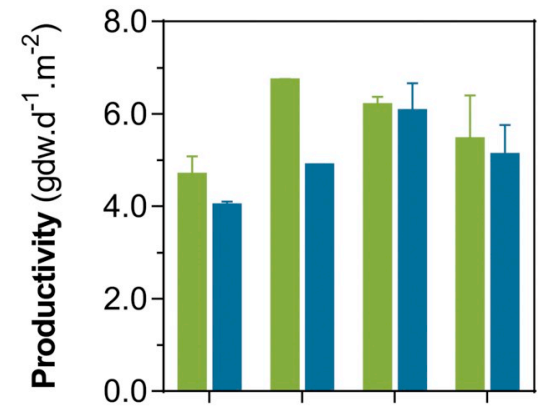

C

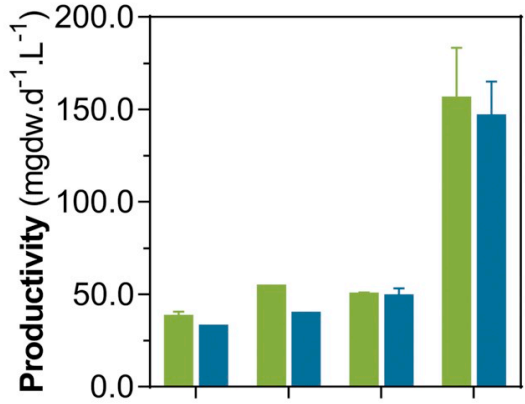

D

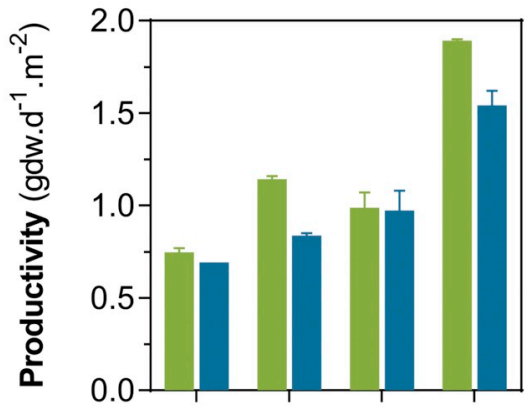

$\mathbf{E}$

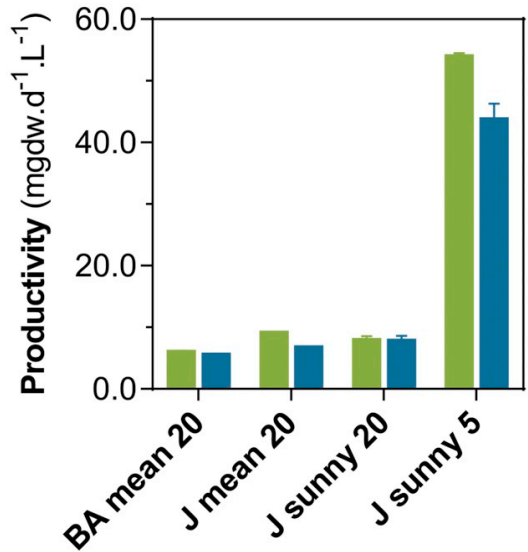

Fig. 5. Environmental photobioreactors analysis of matching Scenedesmus spp. strains origin and simulated weather conditions. A, Final biomass concentration; B, biomass areal productivity; C, biomass volumetric productivity; D, lipid areal productivity; and E, lipid volumetric productivity. Black bars, strain C1S (Buenos Aires); and grey bars, strain P31 (Jujuy). BA mean 20, mean weather conditions of Buenos Aires and $20 \mathrm{~cm}$-deep ponds; J mean 20, mean weather conditions of Jujuy and $20 \mathrm{~cm}$-deep ponds; J sunny 20 and 5, only sunny days in Jujuy and $20 \mathrm{~cm}$ - or $5 \mathrm{~cm}$-deep ponds. Data represent the mean and range of two independent experiments.

Aires strain under mean weather conditions of Jujuy, which resulted $40 \%$ more productive than the native strain (Fig. 5). Similar results were recently shown for a Spirulina sp. strain that had been isolated in Southern Brazil but resulted more productive in open raceway ponds run in the Northeastern than in the Southern region of that country in winter (de Jesus et al., 2018). Also an Antarctic Chlorella sp. strain appeared to be tolerant to a wider range of high temperatures and recovered sooner from stressing high temperatures than a temperate or a tropical Chlorella sp. strains (Barati et al., 2018). This physiological response is quite often displayed by some microbes from extreme environments that slowdown its metabolism under the prevailing stressing conditions but efficiently activate pathways for biomass production during short periods of permissive conditions (Piette et al., 2011).

These results led us to suggest that, at least for some particular cases, strains already adapted to a specific geographical region not necessarily would outperform exotic strains in short-cycle outdoors cultivation-systems. The artificial nature of the productive systems might dictate stronger adaptive responses in the near term than more general ecological drivers, as they naturally occurred in the environment in longer periods of time. A related concept has been used quite successfully, for example, for the massive cultivation of extremophiles such as Spirulina sp. or Dunalliela sp. in high $\mathrm{pH}$ or saline medium, respectively, to dissuade potential native competitors in productive geographical regions (Varshney et al., 2015). Thus, for conciliating increasing microalgal biomass production and ecological safety, a hypothetical win-win situation of a highly productive strain, regardless of its origin, under artificial culture conditions, but poorly adapted to the surrounding natural environment of the cultivation site would be highly desirable. Extremely short-cycle cultivation in hybrid systems comprising large volume inoculum preparation in photobioreactors and fast induction of target product accumulation in open raceway ponds (Narala et al., 2016) would additionally take advantage of this kind of opportunistic algal strains. Thus, in addition to bioprospecting for microalgae native to candidate productive sites, this study might suggest consideration of those opportunistic algae from less stable and yearround less productive sites. Nevertheless, regional water chemistry and robustness against potential native competitors and grazers, among other aspects, should also be considered in further analysis of this concept.

Although a detailed modeling of the absolute algal productivity in the region is beyond the scope of this study, these data allowed us to make some preliminary calculations. We showed productivities for ePBR-simulated outdoors cultivation of $S$. obliquus strain C1S up to $6.8 \mathrm{~g} \mathrm{~m}^{-2}$ day $^{-1}$ in Jujuy, in autumn (Fig. 4). A recent study found that biomass productivity simulations in ePBRs were $44 \%$ lower than outdoor pond culturing of Chlorella sorokiniana in Arizona (Huesemann et al., 2017). Then, accounting for the available information on possible uncertainties of ePBR simulations, productivity for strain C1S could be from 6.8 to $9.8 \mathrm{~g} \cdot \mathrm{m}^{-2}$. day ${ }^{-1}$ in Jujuy, in autumn. This productivity is somehow close to the current state-of-the-art annual average productivity of $8.5 \mathrm{~g} \cdot \mathrm{m}^{-2}$.day ${ }^{-1}$, but still far away to the $25 \mathrm{~g} \cdot \mathrm{m}^{-2}$.day ${ }^{-1}$ that would be required to approach target production costs (Huesemann et al., 2018). Unlike most previous simulation studies (Huesemann et al., 2018; Huesemann et al., 2017; Huesemann et al., 2013; Moody et al., 2014; Pegallapati and Nirmalakhandan, 2012), in this work we did not supplement $\mathrm{CO}_{2}$ to the cultures in part because the 
Jujuy high-lands is mostly an undeveloped region and industrial $\mathrm{CO}_{2}$ waste might not be a readily accessible resource for this geographical site. Nevertheless, the response of $S$. obliquus $\mathrm{C} 1 \mathrm{~S}$ to $\mathrm{CO}_{2}$ supplementation in bubbled columns run under laboratory conditions has suggested a 4-fold enhancement of biomass productivity (Do Nascimento et al., 2012).

This work further confirms the convenience of using devices such as ePBRs for low cost and low risk assessment of potential productivity of native or exotic microalgal strains on any geographical region. As recently proposed, ePBRs appear to be highly reliable in terms of producing surprisingly consistent results (Huesemann et al., 2017), since replicas produced over the course of more than one year after randomizing the scripts and the ePBR units showed very similar values most of the times. Nevertheless, it is important take into account that ePBRs are simulation devises that oversimplify the complexity of outdoors cultivation of microalgae for weather homogenization, light spectrum, avoidance of contamination and predation, turbulence, etc.

\section{Conclusions}

This work shows the isolation and basic biochemical characterization of twenty-six microalgal strains from a high-altitude and high-irradiance geographical site. We provided a case study for $S$. obliquus strains that shows that native strains appear to be more productive under specific weather conditions in agreement with its origin. However, the overall highest areal productivity corresponded to a nonnative strain in a higher-irradiance geographical site, suggesting the possibility of disclosing the productivity potential of opportunistic strains in more stable and permissive weather conditions.

\section{Declaration of interest}

None.

\section{Acknowledgements}

We thank ME Sanz Smachetti for editorial revision of the Ms. CDC is doctoral fellows at the CONICET and L.C. is a career researcher at the CONICET, Argentina. This work was supported by Grant PICT2015 3559 from the Agencia Nacional de Promoción Científica y Tecnológica to LC.

\section{References}

Araujo, G.S., Matos, L.J.B.L., Gonçalves, L.R.B., Fernandes, F.A.N., Farias, W.R.L., 2011. Bioprospecting for oil producing microalgal strains: evaluation of oil and biomass production for ten microalgal strains. Bioresour. Technol. 102, 5248-5250.

Barati, B., Lim, P.E., Gan, S.Y., Poong, S.W., Phang, S.M., 2018. Gene expression profile of marine Chlorella strains from different latitudes: stress and recovery under elevated temperatures. J. Appl. Phycol. 1-10.

Baudelet, P.H., Ricochon, G., Linder, M., Muniglia, L., 2017. A new insight into cell walls of Chlorophyta. Algal Res. 25, 333-371.

Benemann, J.R., Oswald, W.J., 1996. Systems and economic analysis of microalgae ponds for conversion of $\mathrm{CO}_{2}$ to biomass. In: Final Report, Subcontract XK 4-04136-06, Pittsburgh Energy Technology Center Grant No. DE-FG22-93PC93204.

Bligh, E.G., Dyer, W.J., 1959. A rapid method of total lipid extraction and purification. Can. J. Biochem. Physiol. 37, 911-917.

Bourrelly, P., 1966. Les Algues d'eau douce: Initiation á la systématique: Tome I: Les Algues vertes, Paris.

de Jesus, C.S., da Silva Uebel, L., Costa, S.S., Miranda, A.L., de Morais, E.G., de Morais, M.G., Costa, J.A.V., Nunes, I.L., de Souza Ferreira, E., Druzian, J.I., 2018. Outdoor pilot-scale cultivation of Spirulina sp. LEB-18 in different geographic locations for evaluating its growth and chemical composition. Bioresour. Technol. 256, 86-94.

Del Campo, J.A., García-González, M., Guerrero, M.G., 2007. Outdoor cultivation of microalgae for carotenoid production: current state and perspectives. Appl. Microbiol. Biotechnol. 74, 1163-1174.

Department of Energy, U.S, 2014. Office of Energy Efficiency and Renewable Energy, Biomass Multi-Year Program Plan, July 2014. http://www.energy.gov/sites.

Do Nascimento, M., Ortiz-Marquez, J.C.F., Sanchez-Rizza, L., Echarte, M.M., Curatti, L. 2012. Bioprospecting for fast growing and biomass characterization of oleaginous microalgae from South-Eastern Buenos Aires, Argentina. Bioresour. Technol. 125, 283-290.
Dreywood, R., 1946. Qualitative test for carbohydrate material. Ind. Eng. Chem. 18, 499. https://solargis.com/maps-and-gis-data/download/argentina.

Huesemann, M.H., Van Wagenen, J., Miller, T., Chavis, A., Hobbs, S., Crowe, B., 2013. A screening model to predict microalgae biomass growth in photobioreactors and raceway ponds. Biotechnol. Bioeng. 110, 1583-1594.

Huesemann, M., Dale, T., Chavis, A., Crowe, B., Twary, S., Barry, A., Valentine, D., Yoshida, R., Wigmosta, M., Cullinan, V., 2017. Simulation of outdoor pond cultures using indoor LED-lighted and temperature-controlled raceway ponds and Phenometrics photobioreactors. Algal Res. 21, 178-190.

Huesemann, M., Chavis, A., Edmundson, S., Rye, D., Hobbs, S., Sun, N., Wigmosta, M., 2018. Climate-simulated raceway pond culturing: quantifying the maximum achievable annual biomass productivity of Chlorella sorokiniana in the contiguous USA. J. Appl. Phycol. 30, 287-298.

Kumar, S., Nei, M., Dudley, J., Tamura, K., 2008. MEGA: a biologist-centric software for evolutionary analysis of DNA and protein sequences. Brief. Bioinform. 9, 299-306.

Lammers, P.J., Huesemann, M., Boeing, W., Anderson, D.B., Arnold, R.G., Bai, X., Bhole, M., Brhanavan, Y., Brown, L., Brown, et al., 2017. Review of the cultivation program within the National Alliance for Advanced Biofuels and Bioproducts. Algal Res. 22, 166-186.

Li, Y., Han, D., Hu, G., Dauvillee, D., Sommerfeld, M., Ball, S., Hu, Q., 2010. Chlamydomonas starchless mutant defective in ADP-glucose pyrophosphorylase hyper-accumulates triacylglycerol. Metab. Eng. 12, 387-391.

Loera-Quezada, M.M., Leyva-González, M.A., Velázquez-Juárez, G., Sanchez-Calderón, L. Do Nascimento, M., López-Arredondo, D., Herrera-Estrella, L., 2016. A novel genetic engineering platform for the effective management of biological contaminants for the production of microalgae. Plant Biotechnol. J. 14, 2066-2076.

Lowry, O.H., Rosebrough, N.J., Farr, A.L., Randall, R.J., 1951. Protein measurement with the Folin phenol reagent. J. Biol. Chem. 193, 265-275.

Lucker, B.F., Hall, C.C., Zegarac, R., Kramer, D.M., 2014. The environmental photobioreactor (ePBR): an algal culturing platform for simulating dynamic natural environments. Algal Res. 6, 242-249.

Mishra, S.K., Suh, W.I., Farooq, W., Moon, M., Shrivastav, A., Park, M.S., Yang, J.-W., 2014. Rapid quantification of microalgal lipids in aqueous medium by a simple colorimetric method. Bioresour. Technol. 155, 330-333.

Moody, J.W., McGinty, C.M., Quinn, J.C., 2014. Global evaluation of biofuel potential from microalgae. Proc. Natl. Acad. Sci. U. S. A. 111, 8691-8696.

Mutanda, T., Ramesh, D., Karthikeyan, S., Kumari, S., Anandraj, A., Bux, F., 2011. Bioprospecting for hyper-lipid producing microalgal strains for sustainable biofuel production. Bioresour. Technol, 102, 57-70.

Narala, R.R., Garg, S., Sharma, K.K., Thomas-Hall, S.R., Deme, M., Li, Y., Schenk, P.M., 2016. Comparison of microalgae cultivation in photobioreactor, open raceway pond, and a two-stage hybrid system. Front. Energy Res. 4 (29). https://doi.org/10.3389/ fenrg.2016.00029.

Nascimento, I.A., Marques, S.S.I., Cabanelas, I T.D., Pereira, S.A., Druzian, J.I., de Souza, C.O., Vich, D.V., de Carvalho, G.C., Nascimento, M.A., 2013. Screening microalgae strains for biodiesel production: Lipid productivity and estimation of fuel quality based on fatty acids profiles as selective criteria. Bioenergy Res. 6, 1-13.

Pegallapati, A.K., Nirmalakhandan, N., 2012. Modeling algal growth in bubble columns under sparging with $\mathrm{CO}_{2}$-enriched air. Bioresour. Technol. 124, 137-145.

Piette, F., D'Amico, S., Mazzucchelli, G., Danchin, A., Leprince, P., Feller, G., 2011. Life in the cold: a proteomic study of cold-repressed proteins in the Antarctic bacterium Pseudoalteromonas haloplanktis TAC125. Appl. Environ. Microbiol. 77, 3881-3883.

Pruvost, J., Van Vooren, G., Le Gouic, B., Couzinet-Mossion, A., Legrand, J., 2011. Systematic investigation of biomass and lipid productivity by microalgae in photobioreactors for biodiesel application. Bioresour. Technol. 102, 150-158.

Rippka, R., Deruelles, J., Waterbury, J.B., Herdman, M., Stanier, R.Y., 1979. Generic assignments, strain histories and properties of pure cultures of Cyanobacteria. Microbiol. 111, 1-61.

Rondanelli, R., Molina, A., Falvey, M., 2015. The Atacama surface solar maximum. Bull. Am. Meteorol. Soc. 96, 405-418.

Sanchez Rizza, L., Sanz Smachetti, M.E., Do Nascimento, M., Salerno, G.L., Curatti, L., 2017. Bioprospecting for native microalgae as an alternative source of sugars for the production of bioethanol. Algal Res. 22, 140-147.

Sheehan, J.T., Dunahay, T., Benemann, J., Roesler, P., 1998. A look back at the U.S. Department of Energy's Aquatic Species Program: biodiesel from algae. In: Report NREL/TP-580-24190. National Renewable Energy Laboratory.

Slade, R., Bauen, A., 2013. Micro-algae cultivation for biofuels: cost, energy balance, environmental impacts and future prospects. Biomass Bioenergy 53, 29-38.

Spolaore, P., Joannis-Cassan, C., Duran, E., Isambert, A., 2006. Commercial applications of microalgae. J. Biosci. Bioeng. 101, 87-96.

Stamenković, M., Hanelt, D., 2013. Adaptation of growth and photosynthesis to certain temperature regimes is an indicator for the geographical distribution of Cosmarium strains (Zygnematophyceae, Streptophyta). Eur. J. Phycol. 48, 116-127.

Steinrücken, P., Erga, S.R., Mjøs, S.A., Kleivdal, H., Prestegard, S.K., 2017. Bioprospecting North Atlantic microalgae with fast growth and high polyunsaturated fatty acid (PUFA) content for microalgae-based technologies. Algal Res. 26, 392-401.

Timmins, M., Thomas-Hall, S.R., Darling, A., Zhang, E., Hankamer, B., Marx, U.C. Schenk, P.M., 2009. Phylogenetic and molecular analysis of hydrogen-producing green algae. J. Exp. Bot. 60, 1691-1702.

Vandamme, D., Foubert, I., Muylaert, K., 2013. Flocculation as a low-cost method for harvesting microalgae for bulk biomass production. Trends Biotechnol. 31, 233-239.

Varshney, P., Mikulic, P., Vonshak, A., Beardall, J., Wangikar, P.P., 2015. Extremophilic micro-algae and their potential contribution in biotechnology. Bioresour. Technol. 184, 363-372.

Wellburn, A.R., 1994. The spectral determination of chlorophylls $a$ and $b$, as well as total carotenoids, using various solvents with spectrophotometers of different resolution. J. Plant Physiol. 144, 307-313. 